\title{
Displacement-based design of Reinforced Concrete Special Moment Frame (RC-SMF) with Vertical Irregularity
}

\author{
A F M Salman Akhter ${ }^{1}$, and Yoyong Arfiadi ${ }^{2 *}$ \\ ${ }^{1}$ Department of Civil Engineering, Universitas Atma Jaya Yogyakarta, 55281 Yogyakarta, Indonesia \\ ${ }^{2}$ Department of Civil Engineering, Universitas Atma Jaya Yogyakarta, 55281 Yogyakarta, Indonesia
}

\begin{abstract}
Reinforced concrete Special Moment Frame (RC-SMF) with irregularity in dimension experiences large inelastic deformation under ground motion. The building code for designing structural elements generally is focused on satisfying the strength and serviceability. On the other hand, the displacement-based design (DBD) procedure is based on building performance level. This paper presents a devoted study of designing structural elements of 8 story RC-SMF with vertical irregularity using the DBD method. This method is mainly using energy-work balance concept with pre-selected yield mechanism and target drift. Moreover, a new lateral force distribution method is used in this study which accounts for inelastic dynamic response and higher mode effects. Strong column-weak beam mechanism is used to design beam and column, and beam moment capacity of each floor is calculated by equating external work to internal work approach. Furthermore, column design strength is taken as the combination of factored gravity loads and maximum expected strength of the beam. The time history analysis results show that story drift is below than the target drift and achieve the desired performance level. Moreover, the results also show lateral force distribution is very close to the lateral shear distribution which obtained from time history analysis.
\end{abstract}

\section{Introduction}

The displacement based design method is based on strong-column weak-beam concept and used a predetermined yield mechanism and target drift. The main benefit of this method is the failures first occur in the beam, not in the column. As a result, the total collapse of the building is prevented and the life safety of structure improved. Due to damage and undesired failure of the structural and non-structural member of code based reinforced concrete (RC) building under severe ground motion [1] have indicated the need to improve the design methodology for better structural performance. However, the present design codes [2, 3] have special requirements for the designing of $\mathrm{RC}$ buildings. Recently, a displacement based design method is namely Performance Based Plastic Design (PBPD) [4] has been achieved excellent performance against earthquake loading. Since, the irregular shaped RC SMF is widely used as an earthquake resisting structure, a enhance research has been performed using this method to obtain the satisfactory performance level.

A new design procedure of structure which has one or more performance objectives to meet is referred as Performance-Based Seismic Design (PBSD) [5]. The main objective of Performance-Based Seismic Design (PBSD) is to develop design methodologies for predictable and intended seismic performance of structure under stated level of seismic hazards $[5,6]$.
This concept becomes very popular among the design engineers and researchers who were searching a design approach where all variables that affect the performance of building like interstory drift ratio, floor acceleration, damage measure, collapse etc. will be involved [7]. After several comprehensive research, a performance-based design method using target drift and yield mechanism is carried out on the different type of steel structure like Eccentrically Braced Frame (EBF), Concentrically Braced Frame (CBF), and Special Moment Truss Frames (STMF) [8-12]. Furthermore, this method is also applied to the reinforced concrete structure to validate this methodology on RC structure $[12,13]$. In this study, an 8 story RC-SMF with vertical irregularity is designed using this method and perform the time-history analysis.

The 8 story vertically irregular shaped RC SMF is completely designed using the proposed displacementbased design where work-energy equation is used to calculate the design base shear, and a new lateral force distribution is used which include the inelastic dynamic response and higher mode effects [8]. The target response spectrum is taken from [14] for soil type E (soft soil) of Yogyakarta. After designing the same structure using the code based method, a nonlinear time history analysis is performed by using OpenSees 2.5.0 platform [15] and the resulting interstory drift and story shear distribution are compared.

* Corresponding author 


\section{Displacement based design}

The performance of a structure mostly depends on ductility demand, displacement, and inter-story drift under severe earthquake. The displacement-based design considers the effect of ductility demand, displacement, interstory drift and others factor while designing components of the structure. It is also noted that this method can also be used to achieve the performance level for various hazard levels. As a result, the displacement-based design method is considered as the main function of performance-based design.

\subsection{Energy balance concept}

The main point of the energy-work concepts is the work need to push the structure up to a target drift is equal to the energy need of an equivalent elastic-plastic singledegree-of-freedom (EP-SDOF) system to achieve the same condition which is shown in Figs.1 and 2, and following:

$$
\left(E_{e}+E_{p}\right)=\gamma \cdot\left(\frac{1}{2} M \cdot S_{v}^{2}\right)=\frac{1}{2} \gamma \cdot M\left(\frac{T}{2 \pi} S_{a} \cdot g\right)^{2}
$$

where $E_{e}$ and $E_{p}$ are elastic and plastic component respectively of total energy needed to push the structure up to the target drift. The $S_{v}$ and $S_{a}$ are the design pseudo-spectral velocity and pseudo-spectral acceleration respectively, $T$ is natural period and $M$ is total mass of the structure.

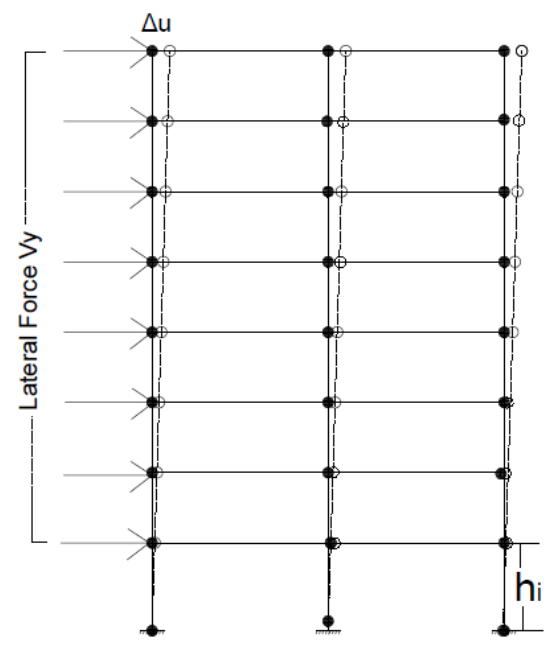

Fig. 1. Structure push upto target drift (work-energy balance concept) [8]

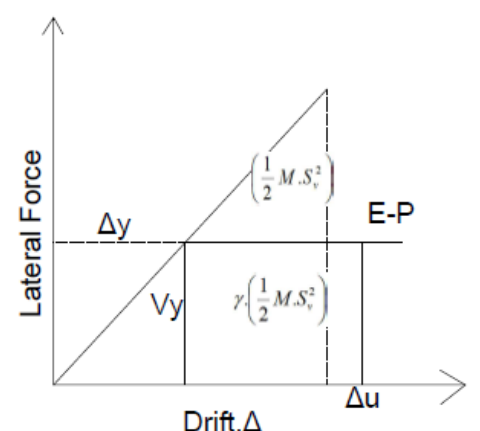

Fig. 2. Required enegrgy by elastic-plastic-single degree-offreedom system (work-energy balance concept) [8]

\subsubsection{Design Base Shear}

Equation (1) is further modified and get the energy modification factor $\gamma$ which is used to calculate the design base shear [13]:

$$
\gamma=\frac{2 \mu_{s}-1}{R_{\mu}^{2}}
$$

where, $R_{\mu}$ is ductility reduction factor which is obtained from Table 1 [16] and $\mu_{s}$ is structural ductility factor.

Table 1. Ductility reduction factor and time [16]

\begin{tabular}{|c|c|}
\hline Time & Ductility reduction factor \\
\hline $\mathrm{T}_{1} \leq \mathrm{T}$ & $R_{\mu}=\mu_{s}$ \\
$\mathrm{~T}_{1}=0.57 \mathrm{sec}$ & \\
\hline
\end{tabular}

The work-energy equation (1) can be modified and re-written in the following form:

$$
\frac{V_{y}}{W}=\frac{-\alpha+\sqrt{\alpha^{2}+4 \cdot \gamma \cdot S_{a}^{2}}}{2}
$$

where $V_{y} / W$ is design base shear coefficient, $\alpha$ is a dimensionless parameter given by following formula:

$$
\alpha=\left(\sum_{j=1}^{n}\left(\beta_{i}-\beta_{i+1}\right) \cdot h_{i}\right) \cdot\left(\frac{w_{n} h_{n}}{\sum_{j=1}^{n} w_{j} h_{j}}\right)^{0.75 T^{-0.2}}\left(\frac{\theta_{p} 8 \pi^{2}}{T^{2} g}\right)
$$

where $V_{y}$ is the design base shear determined by workenergy equation, $\mathrm{W}$ is the total seismic weight of the structure, $w_{n}$ and $w_{j}$ is top floor seismic weight and $\mathrm{j}$-th floor seismic weight respectively, $h_{n}$ and $h_{j}$ is the structure height at top floor and $j$-th floor respectively, $\beta_{i}$ is the shear distribution factor and $\theta_{p}$ is plastic component of target drift ratio. 


\subsubsection{Lateral force distribution}

The shear distribution factor and lateral force distribution is obtained from inelastic dynamic response formula [13] which is given as:

$$
\begin{gathered}
\frac{V_{i}}{V_{n}}=\beta_{i}=\left(\frac{\sum_{j=1}^{n} w_{j} h_{j}}{w_{n} h_{n}}\right)^{0.75 T^{-0.2}} \\
V_{i}=\left(\frac{\sum_{j=i}^{n} w_{j} h_{j}}{\sum_{j=1}^{n} w_{j} h_{j}}\right)^{0.75 T^{-0.2}} . V_{y} \\
V_{n}=F_{n}=\left(\frac{w_{n} h_{n}}{\sum_{j=1}^{n} w_{j} h_{j}}\right)^{0.75 T^{-0.2}} . V_{y}
\end{gathered}
$$

where $V_{i}$ and $V_{n}$ is static story shear at level $i$ and top level n respectively. $F_{n}$ is lateral force at top floor $n$. For lateral force at i level, $F$, the formula is given as:

$$
F_{i}=\left(\beta_{i}-\beta_{i+1}\right) \cdot\left(\frac{w_{n} h_{n}}{\sum_{j=1}^{n} w_{j} h_{j}}\right)^{0.75 T^{-0.2}} \cdot V_{y}
$$

\subsubsection{Beam design}

The beam moment capacity of each floor is calculated using plastic design approach which is external work equal to internal work. The work equilibrium formula is shown below:

$$
\sum_{i=1}^{n} F_{i} h_{i} \theta=2 M_{p c} \theta+\sum_{i=1}^{n} 2\left(\beta_{i} M_{p b}\right) \gamma_{i}
$$

where $\theta$ is small kinematic rotation angle of yield mechanism, $M_{p b}$ is the beam moment strength which is sum of positive and negative moment, $M_{p c}$ is plastic moment of column at base and $\gamma_{i}$ is the rotational term. Equation (9) is further simplified to calculate the beam positive and negative moment, and the equations are given below:

$$
\sum_{i=1}^{n} F_{i} h_{i} \theta_{p}=2 \cdot M_{p c} \theta_{p}+\sum_{i=1}^{n} 2 \beta_{i}(1+x .) M_{p b(+)} \cdot \gamma_{i}
$$

$$
\sum_{i=1}^{n} F_{i} h_{i} \theta_{p}=2 \cdot M_{p c} \theta_{p}+\sum_{i=1}^{n} 2 \beta_{i}\left(\frac{1+x}{x} .\right) M_{p b(-)} \cdot \gamma_{i}
$$

where $x$ is the ratio of negative to positive beam moment.

\subsubsection{Column design}

In this study, the strength in column is taken as a combination of factored gravity loads and maximum expected strength of the beam. Using this concept, exterior and interior column tree is drawn which is the main function of column design. For determining axial load acting on column, the formula is given below:

$$
\begin{gathered}
V_{i}=\frac{\left|M_{p r(+)}\right|_{i}+\left|M_{p r(-)}\right|_{i}}{L^{\prime}}+\frac{w_{i-\text { tributary }} . L^{\prime}}{2} \\
V_{i}^{\prime}=\frac{\left|M_{p r(+)}\right|_{i}+\left|M_{p r(-)}\right|_{i}}{L^{\prime}}-\frac{w_{i-\text { tributary }} \cdot L^{\prime}}{2}
\end{gathered}
$$

where $M_{p r(+)}$ and $M_{p r(-)}$ are the beam positive and negative moments, respectively which are multiplying with a factor 1.25 [17], and L' is the beam length between two hinges. The shear distribution factor $\alpha_{i}$ and shear determination formulas for exterior column $F_{L-e x t}$ and interior column $F_{L-\text { int }}$ are given below:

$$
\begin{gathered}
\alpha_{i} F_{L-e x t}=\frac{\sum_{i=1}^{n}\left(M_{p r-}\right)_{i}+\sum_{i=1}^{n} V_{i}\left(\frac{L-L^{\prime}}{2}\right)_{i}+M_{p c}}{\sum_{i=1}^{n} \alpha_{i} h_{i}} \\
\alpha_{i} F_{L-\text { int }}=\frac{\sum_{i=1}^{n}\left(\left|M_{p r-}\right|_{i}+\left|M_{p r+}\right|_{i}\right)+\sum_{i=1}^{n}\left[V_{i}+V_{i}^{\prime}\right] \cdot\left(\frac{L-L^{\prime}}{2}\right)_{i}+2 M_{p c}}{\sum_{i=1}^{n} \alpha_{i} h_{i}} \\
\alpha_{i}=\frac{\left(\beta_{i}-\beta_{i+1}\right)}{\sum_{i=1}^{n}\left(\beta_{i}-\beta_{i+1}\right)}
\end{gathered}
$$

\section{Design of RC SMF by displacement- based design method}

An 8 story RC SMF with vertical irregularity is taken for the application of this displacement based design and validated using nonlinear time history analysis. The building has 4-bay in both horizontal direction up to $4^{\text {th }}$ floor and the vertical irregularity appears in $5^{\text {th }}$ to $8^{\text {th }}$ floor which is shown in Figs. 3 and 4. 


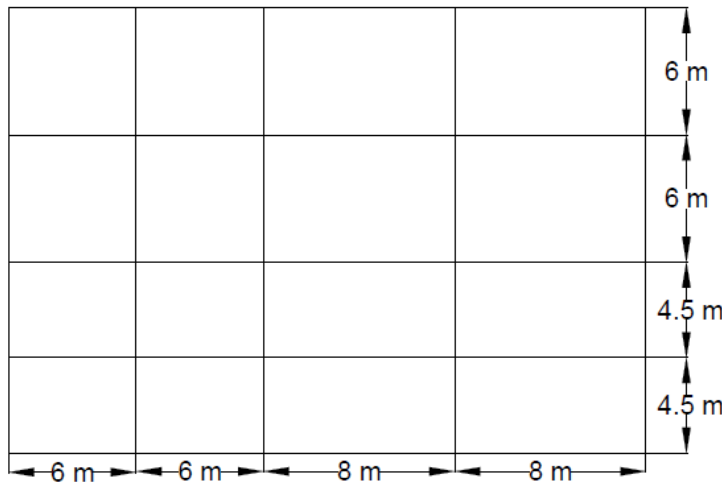

Fig. 3. Floor plan (1 $1^{\text {st }}$ to $4^{\text {th }}$ floor $)$

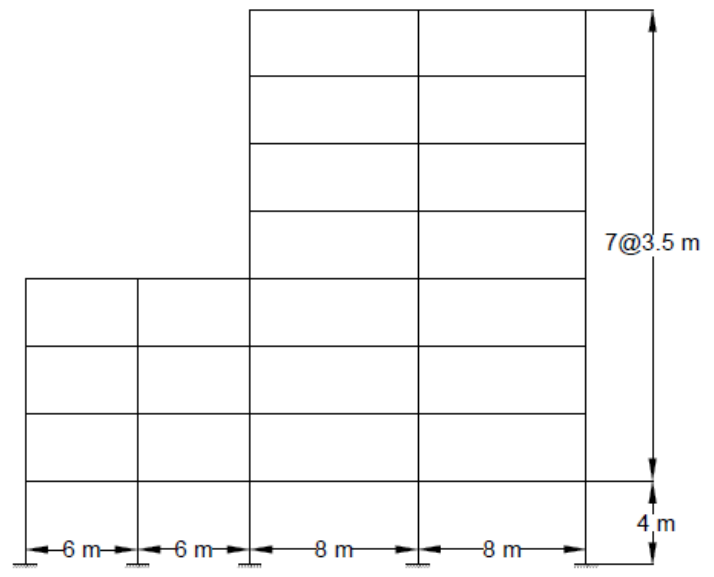

Fig. 4. 8 story RC SMF section view

\subsection{Target response spectrum}

The design response spectrum of all over Indonesia is available online which is managed by PPMB-ITB and PUSKIM [14]. For this study purpose, soil type E (soft soil) of Yogyakarta has been selected. The $\mathrm{S}_{\mathrm{DS}}(\mathrm{g})$ and $\mathrm{S}_{\mathrm{D} 1}(\mathrm{~g})$ values are 0.727 and 0.711 respectively (Fig. 5.).

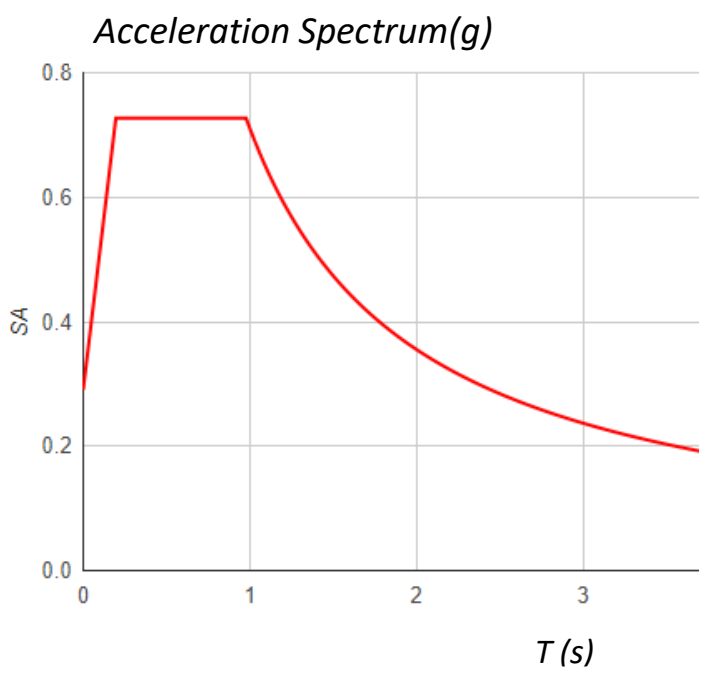

Fig. 5. Target response spectrum (soil type E, Yogyakarta) [14]

\subsection{Design parameters}

The seismic weight of each floor ( $5^{\text {th }}$ to $8^{\text {th }}$ floor) is 716 $\mathrm{kN}$ and ( $1^{\text {st }}$ to $4^{\text {th }}$ floor) $1232 \mathrm{kn}$. The tributary seismic weight for all floor is $44(\mathrm{kN} / \mathrm{m})$. Others parameters are given in Table 2.

Table 2. Design parameters for calculating design base shear of 8 story RC SMF

\begin{tabular}{|c|c|}
\hline Design Parameters & Value \\
\hline No story & 8 \\
\hline Floor height, h (m) & 28.5 \\
\hline Period, $\mathrm{T}$ (sec) & 1.35 \\
\hline Total seismic weight, W $(\mathrm{kn})$ & 7792 \\
\hline $\mathrm{C}_{2}$ & 1.07 \\
\hline Target drift & 0.02 \\
\hline Yield drift & 0.005 \\
\hline Modified target drift & 0.019 \\
\hline Inelastic drift & 0.014 \\
\hline Modified ductility & 3.74 \\
\hline Ductility reduction factor & 3.74 \\
\hline Energy modification factor & 0.46 \\
\hline Dimensionless parameter & 1.30 \\
\hline Spectral acceleration & 0.526 \\
\hline Design base shear (kn) & 718.84 \\
\hline
\end{tabular}

\section{Nonlinear time-history modelling}

In this study, the middle frame of 8 story RC SMF is designed by displacement based method and nonlinear time-history analysis is performed for checking the response of the frame under earthquake loading. The most useful tools is available in present time is OpenSees framework for performing nonlinear analysis. The Open System for Earthquake Engineering Simulation (OpenSees) is a software framework for simulating the seismic response of structural and geotechnical systems. OpenSees has been developed as the computational platform for research in performancebased earthquake engineering at the Pacific Earthquake Engineering Research Center (PEER) [15]. 


\subsection{Material for nonlinear behaviour}

The concrete cover and concrete core properties are defined by using a uniaxialMaterial ConcreteCM which is a uniaxial hysteretic constitutive model for concrete developed by Chang and Mander [18, 19]. The input format for defining this concrete properties is given below:

uniaxialMaterial ConcreteCM \$mattag \$fpcc \$epcc \$Ec \$rc \$xcrn \$ft \$et \$rt \$xcrp <-GapClose \$gap >

uniaxialMaterial ConcreteCM $1-42.75-0.005248566 .4$ 3.004 .2750 .00011 .22 \#Core Concrete

uniaxialMaterial ConcreteCM 1 -27.28 -0.0018 24856

3.431 .892 .7580 .00011 .22 \#Cover Concrete

The steel rebar properties is defined by a uniaxial Giuffre-Menegotto-Pinto steel material. The input format is given below:

uniaxialMaterial Steel02 \$matTag \$Fy \$E \$b \$R0 \$cR1 \$cR2 < \$a1 \$a2 \$a3 \$a4 \$sigInit>

uniaxialMaterial Steel02 24132000000.02180 .925

$0.15<01010>$ \#Steel rebar

\subsection{Section and element}

In this model, fiber section is used to define the beam and column. Each section has concrete cover (in four sides) and concrete core. Rebar is placed according to design. OpenSees has a huge variety of element type for analysis. In this study, Force-Beam-Column element type is selected for our nonlinear modelling. Previously defining section is used with 5 Gauss-Lobatto integration points along the element both for beam and column.

\subsection{Selection of ground motion}

PEER ground motion database [20] is very useful sources for getting ground motion with respect the target response spectrum. In this study, 7 ground motions are selected for performing the time history analysis as given in Table 3.

Table 3. PEER ground motion used in this study

\begin{tabular}{|c|c|c|}
\hline No & Name of Ground Motion & M \\
\hline 1 & Landers & 7.3 \\
\hline 2 & Kobe & 6.9 \\
\hline 3 & Imperial Valley-01 & 6.5 \\
\hline 4 & Imperial Valley-02 & 6.5 \\
\hline 5 & Trinidad & 6.0 \\
\hline 6 & Manjil Abbar & 7.4 \\
\hline
\end{tabular}

\begin{tabular}{|l|l|l|}
\hline 7 & Hollister & 6.5 \\
\hline
\end{tabular}

\subsection{OpenSees analysis option}

The most important part in OpenSees is selecting appropriate analysis option for performing the time history analysis. The analysis option in OpenSees contains 7 parameters to run the analysis which are listed in Table 4. In this study, it is noticed that wrong selection of these parameters resulted unrealistic results or error in sections \& elements, although the model definition is correct. However, the appropriate analysis option selection has given expected and accurate results. On the other hand, in this study, the solution algorithm is needed to change from Newton to modified Newton for different ground motions.

Table 4. OpenSees analysis option parameters for time history analysis

\begin{tabular}{|c|c|}
\hline $\begin{array}{c}\text { Analysis option } \\
\text { parameters }\end{array}$ & Selected type \\
\hline Analysis type & Transient \\
\hline $\begin{array}{c}\text { Constraint handler } \\
\text { type }\end{array}$ & Transformation method \\
\hline $\begin{array}{c}\text { DOF number type } \\
\text { System of equation } \\
\text { type }\end{array}$ & Band general \\
\hline $\begin{array}{c}\text { Convergence test } \\
\text { type }\end{array}$ & Energy increment \\
\hline Solution algorithm & Newton \& modified newton \\
\hline Integrator type & Newmark \\
\hline
\end{tabular}

\section{Analysis results and discussion}

In this study, nonlinear time history analysis is performed to get the structure responses and evaluate the proposed method acceptability. After getting the response of the structure under selected 7 ground motions, the maximum interstory drift and the relative story shear distribution are analysed to understand the performance the structure under real earthquake situation.

\subsection{Maximum interstory drift}

The maximum interstory drift shows the building performance level. The time history analysis results for all 7 selected ground motions are shown in Fig 6 with a mean value. The results show that the story drift for all ground motion is well within the target drift. Moreover, it is also shown that the story drift is evenly distributed over the structure height. However, Imperial Valley-01 and Hollister ground motion has created an unevenly drift distribution. On the other hand, except this two ground motion, the rest ground motions are providing 
very satisfactory drift distribution over the building height. In this graph, it is also shown that the drift ratio is reduced at $5^{\text {th }}$ floor for all ground motion. As the vertical irregularity is started after $4^{\text {th }}$ floor, the result shows that $4^{\text {th }}$ and $5^{\text {th }}$ floor drift difference is very low. However, the results of previous research works [13] for 8 story vertical regular RC SMF showed that the maximum story drift ratio at $5^{\text {th }}$ story increased as compared to above floors.

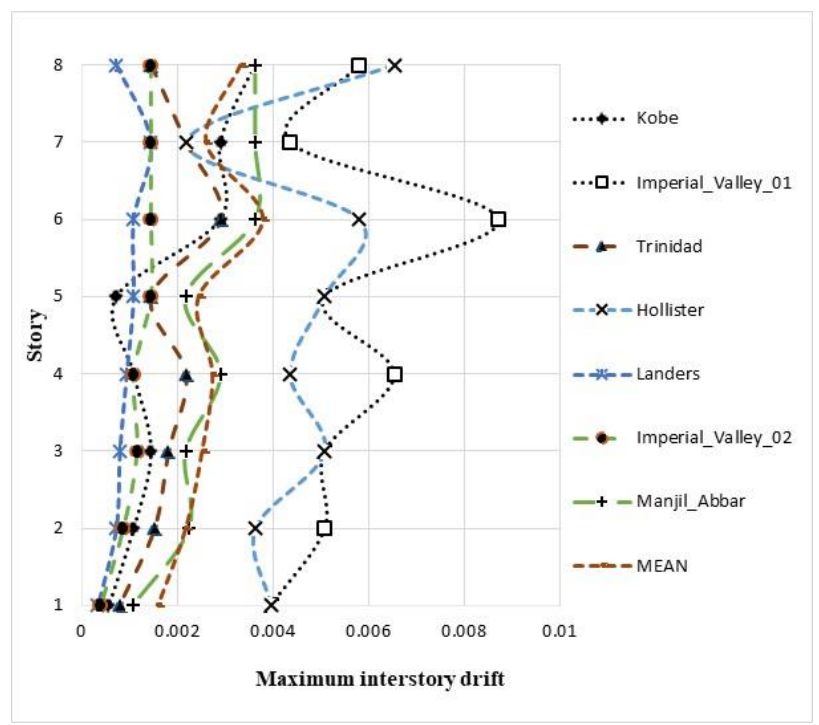

Fig. 6. Maximum interstory drift from time-history analysis of 8 story RC SMF

\subsection{Relative story shear distribution}

It is important to see the output from nonlinear time history analysis, as an inelastic response based lateral force distribution method is used in this study. Fig 7 shows the details of relative story shear distribution for all 7 ground motions. The distribution pattern of relative story shear of the proposed method is similar to the distribution pattern obtained by nonlinear time history analysis of 7 ground motions. Moreover, the result shows that the maximum shear appeared at bottom floor for all ground motions which is 6 to 7.5 times greater than the top floor shear. However, the maximum increment of story shear is appeared at 4th floor for all ground motions including DBD method. Because of the vertical irregularity start from $4^{\text {th }}$ floor the shear distribution pattern is different than the results obtained from previous research work [13] on RC structure. On the other hand, the maximum base shear obtained from 7 ground motions are raged from 650 to $700 \mathrm{kn}$ which is below the design base shear $\left(V_{y}\right)$.

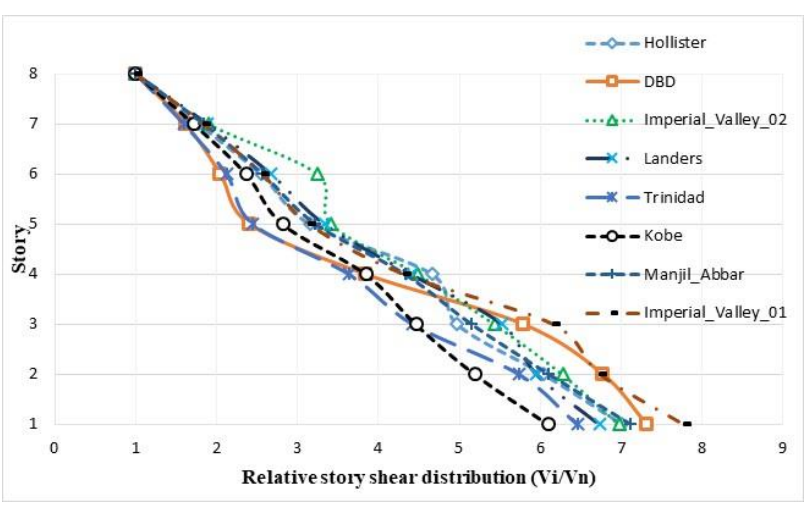

Fig. 7. Relative story shear distribution from time-history analysis of 8 story RC SMF

\section{Conclusion}

The displacement based design method which is based on energy-work balance concept with pre-selected target drift has been considered in this paper. Using this method, an 8 story building is designed and extensive nonlinear time history analysis is performed by using OpenSees with 7 PEER ground motions. The main objective of this research is to prove the validity of this method for RC SMF with vertical irregularity, as some research works have already validated this method for RC SMF regular structure. The results from nonlinear time history analysis show that the achieved drift ratio is below than the pre-selected target drift ratio. In addition, the story distribution patterns is also similar to the inelastic based lateral force distribution method. The major outcome from this enhance study is that the displacement based method proves its validity for both regular and vertically irregular RC SMF structures, and the shear distribution pattern of regular and vertically irregular RC SMF is different because of the presence of structure irregularity.

\section{References}

1. J. P. Moehle, and S. A. Mahin, EarthquakeResistant Concrete Structures - Inelastic Response and Design, ACI SP-127, 67-90(1991)

2. ASCE 7-10, Minimum design loads for buildings and other structures, (2005)

3. ACI 318, Building code requirements for reinforced concrete and commentary (ACI31808/ACI318R-08), (2008)

4. S. C. Goel, W. C. Liao, R. B. Mohammad, and S. H. Chao, Struct. Design Tall Spec. Build., 19, 115-137 (2010)

5. SEAOC, Vision 2000_Performance Based Seismic Engineering of Buildings, (1995)

6. Seismology committee (SEAOC), Recommended lateral force requirements and commentary, (1999) 
7. H. Krawinkler, and E. Miranda, Earthquake Engineering-from Engineering Seismology to Performance-Based Engineering, 523 (2004)

8. S.S. Lee, and S. C. Goel, Report No. UMCEE 0117 (2001)

9. S. H. Chao, and S. C. Goel, Report No. UMCEE 05- 05, (2005)

10. S. H. Chao, and S. C. Goel, AISC Engineering Journal, 3rd, 173-200, (2006)

11. S. H. Chao, and S. C. Goel, Report No. UMCEE 06-03, (2006)

12. S. H. Chao, and S. C. Goel, 4ICEE, Paper No. 227, (2006)

13.S. H. Chao, S. C. Goel, and S.S. Lee, EERI, 23,547-569, (2007)
14.http://puskim.pu.go.id/Aplikasi/desain_spektra ind onesia 2011/, May (2018)

15. PEER,OpenSees 2.5.7, (2018)

16. N. M. Newmark, and W. J. Hall, Earthquake Engrg. Res. Inst, (1982)

17. J. P. Moehle, J. D. Hooper, and C. D. Lubke, NEHRP Seismic Design Technical Brief No. 1. 2008.

18. G.A. Chang, and J.B. Mander, NCEER Technical Report No. NCEER-94-0006, (1994)

19. J.B. Mander, M.J.N. Priestley and R. Park, ASCE Journal of Struct. Engineering, 114, 1804-1826, (1988)

20.https://ngawest2.berkeley.edu/, May, (2018) 